\title{
Combined ground-based optical support for the aurora (DELTA) sounding rocket campaign
}

\author{
Eoghan Griffin ${ }^{1}$, Mike Kosch $^{2,7}$, Anasuya Aruliah ${ }^{1}$, Andrew Kavanagh ${ }^{2}$, Ian McWhirter ${ }^{1}$, Andrew Senior ${ }^{2}$, Elaina Ford $^{1}$, \\ Chris Davis ${ }^{3}$, Takumi Abe ${ }^{4}$, Junichi Kurihara ${ }^{4}$, Kirsti Kauristie ${ }^{5}$, and Yasunobu Ogawa ${ }^{6}$ \\ ${ }^{1}$ Atmospheric Physics Laboratory, University College London, 67-73 Riding House Street, London W1W 7EJ, U.K. \\ ${ }^{2}$ Communication Systems, Lancaster University, Lancaster LA1 4WA, U.K. \\ ${ }^{3}$ Space Science Department, Rutherford Appleton Laboratory, Chilton, Didcot, Oxford OX11 0QX, U.K. \\ ${ }^{4}$ Institute of Space and Astronautical Science, Japan Aerospace Exploration Agency, Sagamihara, Kanagawa 229-8510, Japan \\ ${ }^{5}$ Finnish Meteorological Institute, P. O. Box 503, FIN-00101, Helsinki, Finland \\ ${ }^{6}$ Solar-Terrestrial Environment Laboratory, Nagoya University, Chikusa-ku, Nagoya 464-8601, Japan \\ ${ }^{7}$ Honorary Research Fellow, University of Kwazulu-Natal, Durban 4001, South Africa
}

(Received September 29, 2005; Revised March 25, 2006; Accepted April 12, 2006; Online published September 29, 2006)

The Japan Aerospace Exploration Agency (JAXA) DELTA rocket experiment, successfully launched from Andøya at 0033 UT on December 13, 2004, supported by ground based optical instruments, primarily 2 FabryPerot Interferometers (FPIs) located at Skibotn, Norway $\left(69.3^{\circ} \mathrm{N}, 20.4^{\circ} \mathrm{E}\right)$ and the KEOPS Site, Esrange, Kiruna, Sweden $\left(67.8^{\circ} \mathrm{N}, 20.4^{\circ} \mathrm{E}\right)$. Both these instruments sampled the $557.7 \mathrm{~nm}$ lower thermosphere atomic oxygen emission and provided neutral temperatures and line-of-sight wind velocities, with deduced vector wind patterns over each site. All sky cameras allow contextual auroral information to be acquired. The proximity of the sites provided overlapping fields of view, adjacent to the trajectory of the DELTA rocket. This allowed independent verification of the absolute temperatures in the relatively quiet conditions early in the night, especially important given the context provided by co-located EISCAT ion temperature measurements which allow investigation of the likely emission altitude of the passive FPI measurements. The results demonstrate that this altitude changes from $120 \mathrm{~km}$ pre-midnight to $115 \mathrm{~km}$ post-midnight. Within this large scale context the results from the FPIs also demonstrate smaller scale structure in neutral temperatures, winds and intensities consistent with localised heating. These results present a challenge to the representation of thermospheric variability for the existing models of the region.

Key words: Polar aeronomy, lower thermosphere, Fabry-Perot Interferometer.

\section{Introduction}

The lower thermosphere is a very dynamic region of the atmosphere which represents a challenge to both modelling and experimental efforts. The transition from a regime dominated by turbulent mixing, close to the mesopause, into the higher altitudes where molecular diffusion dominates is dynamically complex. There are also large gradients in both neutral winds and temperatures with altitude through this region and local effects such as the breaking of gravity waves can dominate the amplitude of wind and temperature variations. At high latitudes the impact of geomagnetic activity is evident in the aurora, whose brightest emissions are often generated at lower thermospheric altitudes.

It is a difficult region within which to make remote sensing measurements as few lidars are capable of generating data above $100 \mathrm{~km}$ and there are only a few optical emissions available at these altitudes to be used as a tracer. From the radar perspective the region lies above the range of the meteor radars and the relatively low ionospheric densities

Copyright (c) The Society of Geomagnetism and Earth, Planetary and Space Sciences (SGEPSS); The Seismological Society of Japan; The Volcanological Society of Japan; The Geodetic Society of Japan; The Japanese Society for Planetary Sciences; TERRAPUB can make reliable incoherent scatter radar data difficult to obtain. Given this complex scenario coordinating ground based and in-situ rocket measurements is very important for lower thermosphere studies as both techniques benefit greatly from the contextual information provided by the other. Complex energetics and dynamics are at play in the region, especially at high latitudes. Thus experiments that can combine coverage of as many of the ion and neutral parameters simultaneously from the same region are very important. This is because it is necessary to test and improve our theoretical understanding of the region as a whole.

The combination of unique facilities in the northern scandinavian region consists of the worlds only tristatic incoherent scatter radar (ISR) - EISCAT, rocket and balloon launch facilities (Andøya and Esrange), overlapping field of view FPIs (Skibotn, Keops and Sodankyla), full magnetometer coverage via the IMAGE network and many all-sky cameras (ASC) and meridian scanning photometers (MSP).

The flexibility of the EISCAT radar allows for rapid scanning of different directions and this is important in the context of the ground based support for the DELTA rocket as it provides altitude profiles of the ionospheric parameters in spatially separated samples, close to the trajectory of the DELTA rocket and overlapping the FPI coverage. 
The DELTA rocket launch was therefore planned to produce both in-situ and ground-based remote sensed data from the lower thermosphere with which to investigate the energetics and dynamics of the region in the vicinity of an auroral arc.

\section{Instrument Details}

The ground based support for the DELTA launch consisted of many separate instruments at different locations, some of which were in a standard monitoring mode and others running specific programs to support the rocket launch. An overview of the rocket itself, the launch and payload can be found in Abe et al. (2006).

FPI measurements have been combined with lower thermosphere rocket measurements at high latitudes, e.g. the HEX campaign (Ishii et al., 2004), and incoherent scatter radar measurements have also been separately combined with rocket measurements, e.g. the ISBJØRN campaign (Hall et al., 2000). In the case of the DELTA rocket experiment the combination of ground-based FPI, incoherent scatter radar and in-situ rocket measurements implemented for this experiment is unique.

At both Skibotn, Norway and the Keops site, Esrange, Sweden, FPIs were recording profiles of the $557.7 \mathrm{~nm}$ lower thermosphere atomic oxygen emission (green line). It has been believed that at high latitude the peak emission altitude for the green line is usually around $110 \mathrm{~km}$ to $115 \mathrm{~km}$ (Ishii et al., 2004; Kosch et al., 2000). At high latitude, however, it is known that this peak emission altitude will change as auroral emission due to particle precipitation may dominate and will produce an altitude profile dependent on the incident particle energies. This issue will be discussed fully in the following section. Both FPIs use a 45 degree zenith angle which means the measurements come from a roughly $110 \mathrm{~km}$ horizontal distance away in each direction. At Keops there was also a second FPI which was record-
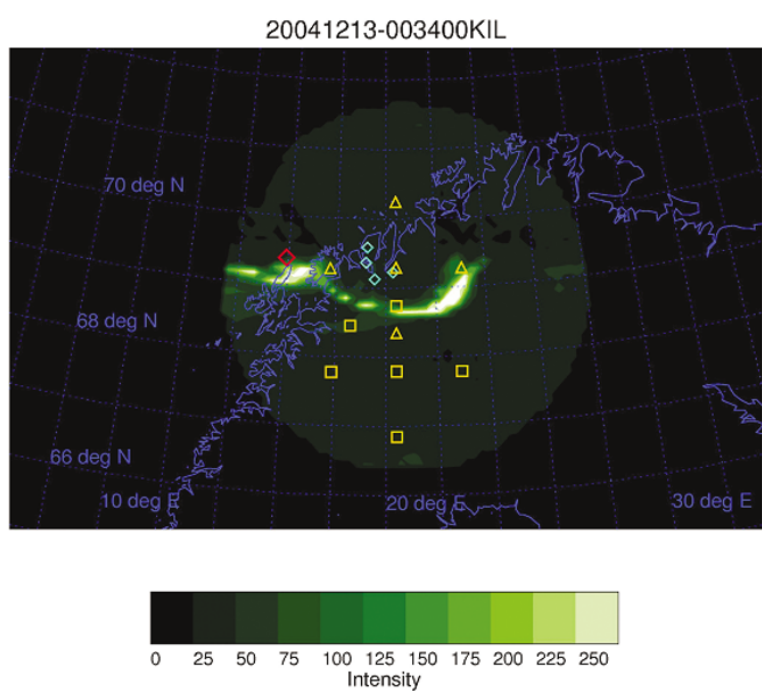

Fig. 1. $557.7 \mathrm{~nm}$ emission as observed by the Finnish Meteorological Institute Kilpisjarvi ASC at 0034 UT. Also included are the projections of the sampled volumes at $110 \mathrm{~km}$ for the Skibotn FPI (brown triangles), Keops FPI (brown boxes), EISCAT CP2 positions (blue diamonds) and the Andoya DELTA rocket launch site (red diamond). ing $630 \mathrm{~nm}$ upper thermosphere emissions from around 240 $\mathrm{km}$. At both Keops and Skibotn the green line instruments operated a normal scan of cardinal directions plus zenith but at Keops one extra direction was included, directed Northwest towards the rocket trajectory. At Keops the integration time of 30 seconds results in a cycle time of just over 8 minutes, at Skibotn the integration time of 10 seconds results in a cycle time of around 7 minutes and 20 seconds. The Keops red line instrument used the scan described in Aruliah et al. (2005), which includes overlapping bistatic volumes with another APL red line FPI at Sodankyla.

The EISCAT UHF radar was operated in CP2 mode which produces a scan of 4 positions including vertical, field-aligned and two positions to the South of the EISCAT Ramfjorden site near Troms $\varnothing$. Of these the vertical and field-aligned positions were the closest to the rocket trajectory. At both Keops and Skibotn ASCs were operated through the night, complementing the coverage provided by the ASC at the launch site, and providing detailed local cloud cover information for both instruments.

The local magnetometers, all part of the IMAGE magnetometer chain, were operating normally and provide important temporal and spatial coverage from which to examine the onset and development of the currents associated with increased auroral activity in the post-midnight period.

This instrumentation is demonstrated in Fig. 1. The figure shows the green line emission as measured by the Kilpisjarvi ASC at 0034 UT. Superimposed on this image are the projections of the sampled volumes at $110 \mathrm{~km}$ for the Skibotn FPI (brown triangles), Keops FPI (brown boxes), EISCAT CP2 positions (blue diamonds) and the Andoya DELTA rocket launch site (red diamond). IMAGE magnetometers are located close to each of these locations.

Figure 1 in Kurihara et al. (2006), this issue, shows the progress of the auroral activity during the rocket flight in great detail.

\section{1 $557.7 \mathrm{~nm}$ emission altitude determination}

As mentioned earlier it has been suggested that the green line emission at high latitude can be associated with an approximate peak altitude of $110 \mathrm{~km}$ (e.g. Ishii et al., 2004), however an important aspect of the combination of EISCAT and FPI measurements is that this assumption can be tested. This is necessary as other authors associate much different altitudes to their observed emissions, e.g. $100 \mathrm{~km}$ for Thuillier et al. (1990) and $115 \mathrm{~km}$ for Price et al. (1995) and Kosch et al. (2000). These estimates for high latitudes are all higher than that expected at either mid-latitude, where Yee and Abreu (1987) measured $95 \mathrm{~km}$, or low latitude where Taylor and Hill (1991) have also used $95 \mathrm{~km}$. These varied estimates of peak emission altitude can be explained by the relative contributions of the airglow and aurora at different latitudes to the overall $557.7 \mathrm{~nm}$ emission profile. At all latitudes an airglow layer around $95 \mathrm{~km}$ exists, characterised by relatively slow changes in intensity. At high latitudes, and in extremely active conditions also at lower latitudes, the auroral $557.7 \mathrm{~nm}$ emission can dominate the overall emission profile. This contribution is characterised by rapid changes in intensity and altitude of emission, and can be expected to dominate the airglow emission at the latitudes of Keops and Skibotn in most conditions. 
Another aspect which underlines the importance of the emission altitude identification is the extent to which the assumption of equivalent ion and neutral temperatures will hold. At altitudes up to $110 \mathrm{~km}$ the ions can be assumed to be closely coupled to the neutrals, since the ion-neutral collision frequency is much larger than the ion gyro-frequency (Thuillier et al., 1990), and hence ion temperatures may be expected to match neutral temperatures. The further above this altitude we find the peak emission altitude to lie, the less likely that the assumptions will be valid. Indeed above $125 \mathrm{~km}$ Thuillier et al. (1990) found that neutral winds deduced from EISCAT measurements, based on these same assumptions, became unreliable.

The EISCAT results provide altitude profiles of ion and electron temperature and these can be used in combination with the FPI results to identify the likely peak emission height for the green line emission. By comparing the time series of EISCAT ion temperature measurements at specific altitudes to corresponding time series of neutral temperatures from the FPIs the likely altitude and variability of the peak emission altitude may be tracked.

Clearly this relies on the emission lying within a region regarded as reliable for the comparison and the combination of the ground based instruments with the in-situ rocket measurements provide a compelling test of whether this is the case for the night in question.

\section{Ground Based Measurements for 12/12/04}

In this section the relevant ground-based measurements made on the night of the DELTA rocket launch, in the vicinity of the rocket trajectory, will be introduced. Many of these measurements can be used together to check on consistency and to a certain extent provide an inter-calibration.

\subsection{FPI measurements}

FPIs are passive optical remote sensing devices and are therefore subject to operational limitations due to the intensity of the emission observed and to the local weather conditions which affect viewing. Therefore clear nightime conditions are necessary for optimal performance. For the night of December 12th the ASCs at Skibton and Keops are used to determine the local conditions. Green line observations were recorded from $1451 \mathrm{UT}$ on $12 / 12 / 04$ to 0710 UT on 13/12/04 at Skibotn and from 1242 UT on 12/12/04 to 0823 UT on $13 / 12 / 04$ at Keops. The differences reflect the different tolerance to dark conditions when using bare CCDs (at Keops) as opposed to an intensified system (at Skibotn). The ASCs at both Skibotn and Keops have been used to determine cloud cover conditions for both sites on the night of the rocket launch. At Skibotn generally cloudy conditions were observed from 1524 UT to 2136 UT. For the remainder of the night clear conditions are indicated. At Keops clear conditions were observed throughout the night. The cloudy conditions will generally render the wind observations from the FPIs based on doppler shifts unreliable, however the temperatures, based on the doppler widths of recorded profiles, are less susceptible to the influence of the cloud cover and can remain informative in all but the worst cloud conditions.

Figure 2 shows the combined FPI temperatures from the Skibotn West look direction compared to the Keops North-

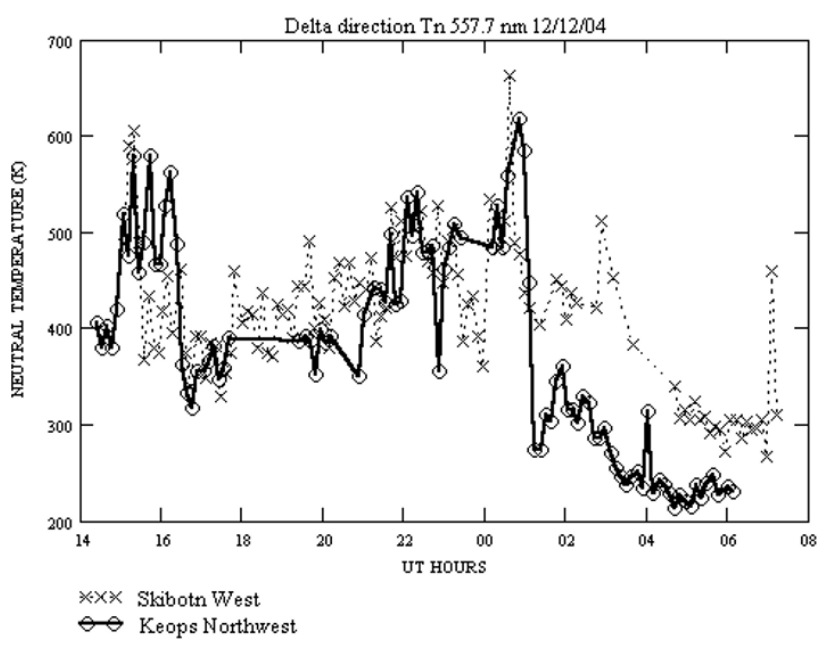

Fig. 2. Lower thermosphere neutral temperatures from 1400 UT on $12 / 12 / 04$ to 0800 UT on $13 / 12 / 04$, determined from the $557.7 \mathrm{~nm}$ emission, observed from the West direction at Skibotn (crosses with dotted line) and from the North-West direction at Keops (circles with solid line).

west look direction for the night of 12/12/04. From Fig. 1 it is possible to see that these are the closest look directions to the DELTA rocket trajectory from each of the FPIs. It is notable that from $1500 \mathrm{UT}$ to $0000 \mathrm{UT}$ the agreement in temperature between the two instruments is very good, which is encouraging given the independent calibration of each instrument. However, while the two FPIs are both directed toward the rocket trajectory their sampled volumes, in the respective look directions, do not overlap. In fact none of the FPI sampled volumes from one FPI has any overlapping common volume the other FPI. Later in the night there are notable and consistent differences between the two sets of temperatures. There are also some periods with few data points from Skibotn West. The missing data is due to the saturation of the detector at Skibotn when sampling intense aurora due to its relatively low dynamic range. The temperature determination relies critically on an accurate fit to the full measured profile, much of which is missing when the profile has a saturation cut-off. Of note in the post-midnight period is a peak in temperature recorded by both instruments between 0000 and $0100 \mathrm{UT}$, these provide the highest temperatures recorded by each instrument during the night and are followed by sharp falls in temperature. The peak in temperature is delayed in the Keops Northwest measurements and the fall in temperature which follows is much higher than that recorded in the Skibotn West measurements, a difference which appears consistent for the remainder of the night. This distinct change in the behaviour of the temperatures in the post-midnight period is accompanied by an increase in geomagnetic activity evident in measurements presented later in this section and this influence will be discussed later.

Figure 3 is similar to Fig. 2, however here we compare the temperatures from the Skibton South look direction to the Keops North look direction. Examining Fig. 1 we can see that these are the 2 closest look volumes when comparing the 2 FPIs. Again we see that the agreement is very good from 1500 UT to 0000 UT. Repeating the pattern seen in 




Fig. 3. Lower thermosphere neutral temperatures from 1400 UT on $12 / 12 / 04$ to 0800 UT on $13 / 12 / 04$, determined from the $557.7 \mathrm{~nm}$ emission, observed from the South direction at Skibotn (crosses with dotted line) and from the North direction at Keops (circles with solid line).

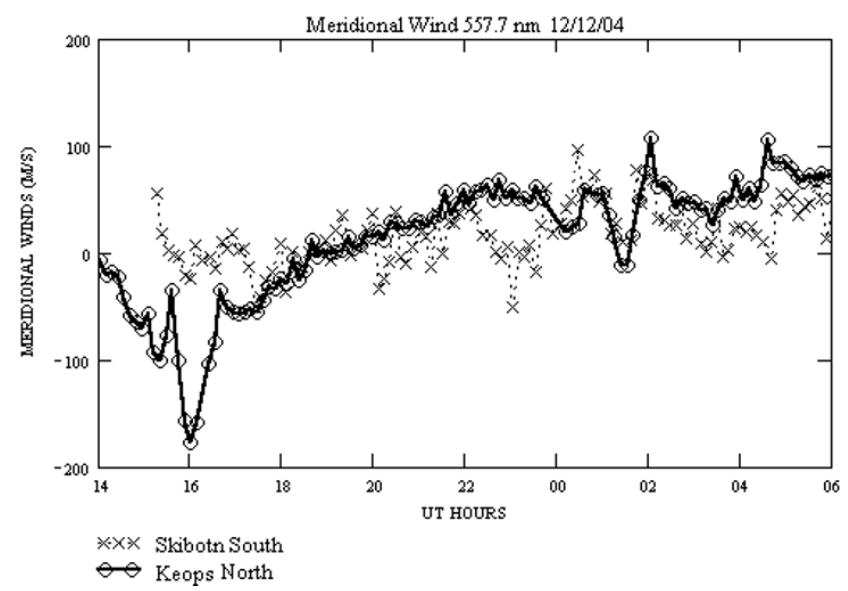

Fig. 4. Lower thermosphere meridional neutral winds from $1400 \mathrm{UT}$ on $12 / 12 / 04$ to 0800 UT on $13 / 12 / 04$, determined from the $557.7 \mathrm{~nm}$ emission, observed from the South direction at Skibotn (crosses with dotted line) and from the North direction at Keops (circles with solid line). Winds are positive in the Southward direction.

Fig. 2 there is a sharp peak in temperature recorded by both FPIs between 0000 UT and 0100 UT which is followed by a sharp decrease in temperature. Also repeated are the consistently lower temperatures measured by the Keops FPI in the later part of the night, although these do eventually appear to match the Skibotn temperatures at the very end of the night. Significantly the temperature peak observed by both FPIs is seen to be coincident in this comparison, without the apparent delay observed in the peaks observed at the same time in Fig. 2. It is likely that this is due to the closer proximity of the look directions in contrast to those being compared in Fig. 3.

As mentioned earlier the cloud conditions in the early part of the night make the wind velocity data from Skibotn unreliable, however after 2136 UT both FPIs experienced clear conditions. In Fig. 4 we can compare the winds from the Keops North and Skibotn South look directions for this period, with Southward winds positive. These directions

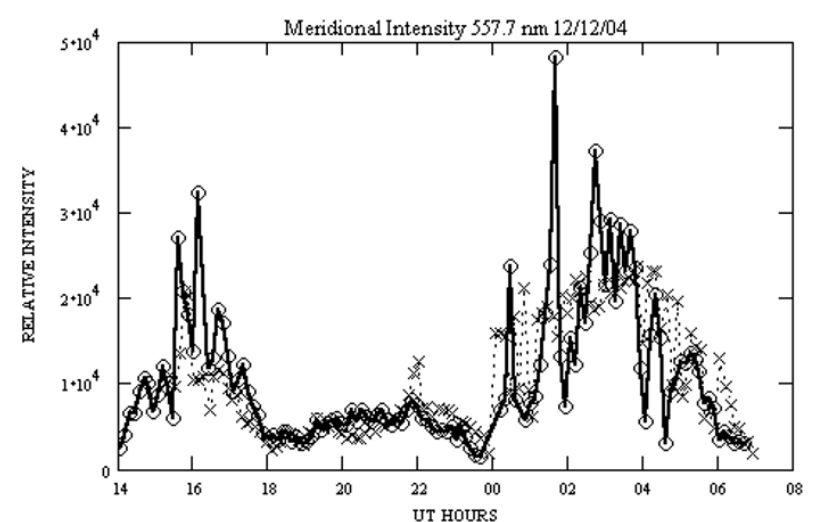

$\ngtr \times \times$ Skibotn South

$\ominus$ Keops North

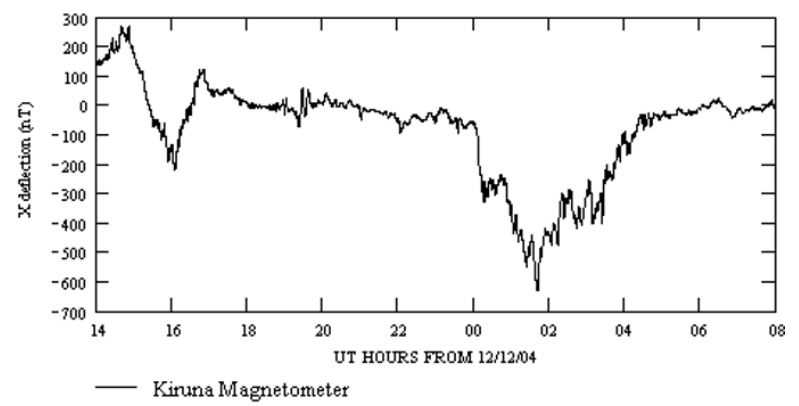

Fig. 5. The top plot shows the $557.7 \mathrm{~nm}$ emission relative intensity from 1400 UT on $12 / 12 / 04$ to 0800 UT on 13/12/04 observed from the South direction at Skibotn (crosses with dotted line) and from the North direction at Keops (circles with solid line). An arbitrary scaling factor has been applied. The bottom plot shows the X-component of magnetic deflection from the Kiruna magnetometer for the same period.

are complementary not just in the sense that they are the closest directions to compare between the two FPIs but also because they are both measuring the meridional component of the wind. We can see in Fig. 4 that the winds from this time show very good agreement, including the period of the DELTA rocket launch.

In the upper panel of Fig. 5 we can see the intensities during the night from Skibotn South and Keops North, i.e. corresponding to the temperatures compared in Fig. 3 and winds compared in Fig. 4, and a correction factor has been applied to the Keops data to provide a match as neither instrument is absolutely calibrated for intensity. In the lower panel in Fig. 5 we show the X-component of the Kiruna magnetometer data from the night. Early in the night, around 1600 UT, an extended deflection of nearly $200 \mathrm{nT}$ is seen to correspond to enhanced intensities in both FPIs. Later the much larger and longer lived disturbances postmidnight, up to $500 \mathrm{nT}$, are associated with consistently higher intensities, however the detector on the Skibotn FPI is limited by saturation and this is reflected in a plateau in the Skibotn South intensities after 0200 UT. It does show, however, that during the time of the DELTA launch the intensities were just below this plateau and so this problem did not influence the winds and temperatures recorded by the Skibotn FPI during this period.

\subsection{EISCAT measurements}

The EISCAT radar was operated in CP-2 mode from 1300 UT on $12 / 12 / 04$ to 0400 UT on $13 / 12 / 04$. This scan 


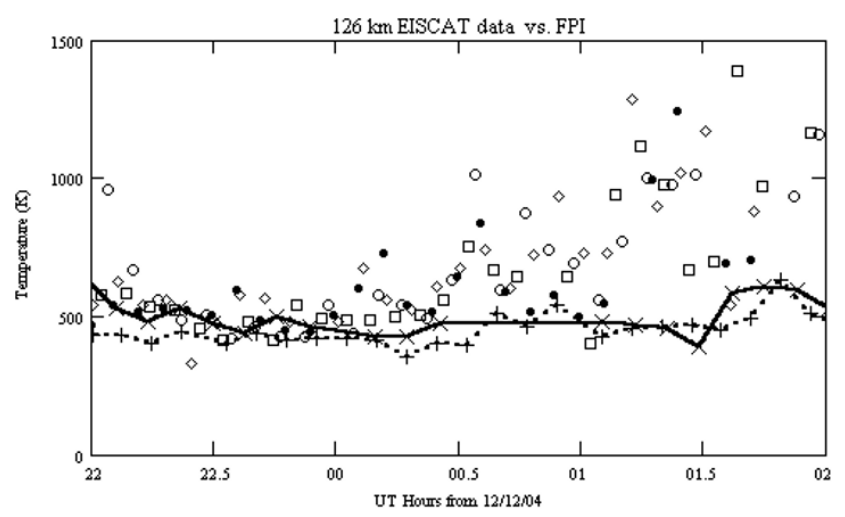

000 CP 2 - (Eastmost) Ion Temperature

वपव CP 2 - (Southmost) Ion Temperature

$\diamond \quad$ CP 2 - (Vertical) Ion Temperature

-. CP 2 - (Field-aligned) Ion Temperature

* $*$ Keops FPI North $557.7 \mathrm{~nm}$ Neutral Temperature

$+\cdot+$ Skibotn FPI South $557.7 \mathrm{~nm}$ Neutral Temperature

Fig. 6. Lower thermosphere neutral temperatures from 2200 UT on $12 / 12 / 04$ to 0200 UT on 13/12/04 from Keops North observations (crosses with solid line) and Skibotn South observations (plusses with dotted line) compared to EISCAT ion temperatures from the CP2 directions (Eastmost—circles, Southmost—boxes, Vertical—diamonds, Field-aligned-filled dots) at $126 \mathrm{~km}$.

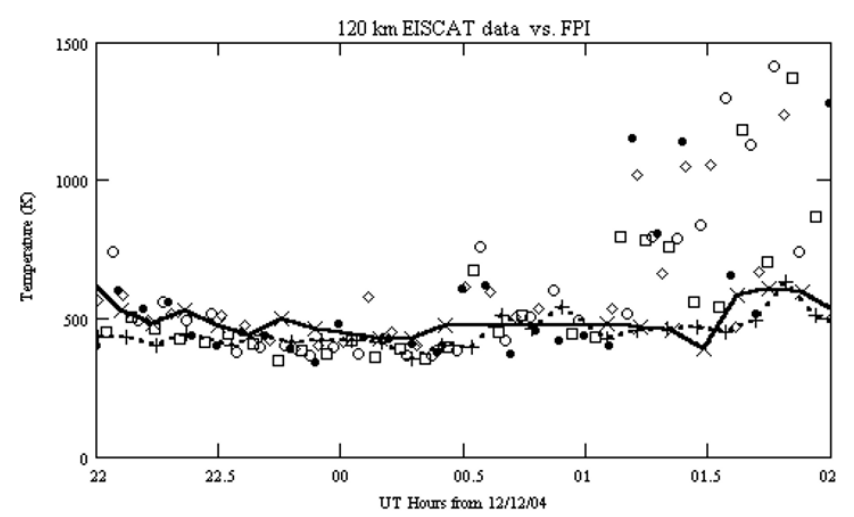

000 CP 2 - (Eastmost) Ion Temperature

प्व CP 2 - (Southmost) Ion Temperature

$\diamond \quad$ CP 2 - Vertical Ion Temperature

$\cdots$ CP 2 - (Field-aligned) Ion Temperature

$*$ K Keops FPI North $557.7 \mathrm{~nm}$ Neutral Temperatur

$+\cdot+$ Skibotn FPI South $557.7 \mathrm{~nm}$ Neutral Temperature

Fig. 7. As for Fig. 6 but EISCAT ion temperatures are from $120 \mathrm{~km}$.

provides 4 positions for the radar: Vertical, field-aligned, a position to the east and one to the south-east. The projection of the radar beam at each of these positions at $110 \mathrm{~km}$ is shown in Fig. 1. All 4 of the scan positions record lower thermosphere data within the field-of-view of the Skibotn FPI, and these measurements lie north of the Keops FPI measurements. At an altitude of $110 \mathrm{~km}$ the Keops and Skibotn FPI sampled volumes are just under $8 \mathrm{~km}$ in horizontal diameter. By comparison the EISCAT beam has a much narrower diameter at this altitude, around $1 \mathrm{~km}$.

As mentioned earlier, in the lower thermosphere the relative abundances of the ions and neutrals means that to a first order the ion and neutral temperatures are equivalent. This allows us to compare the neutral temperatures measured by the FPIs to the ion temperatures measured by the EISCAT radar.

Figure 6 plots the EISCAT ion temperatures at $126 \mathrm{~km}$

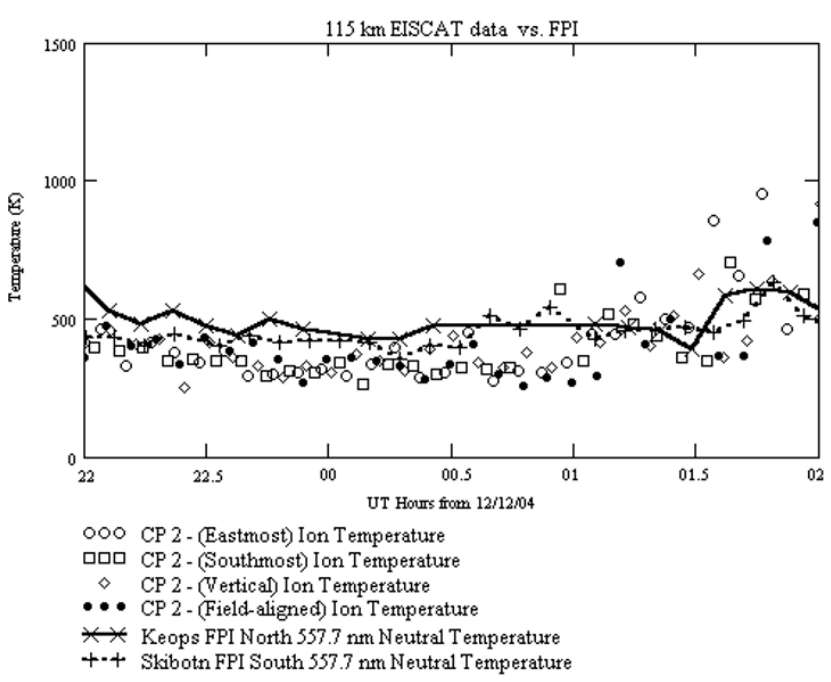

Fig. 8. As for Fig. 6 but EISCAT ion temperatures are from $115 \mathrm{~km}$.

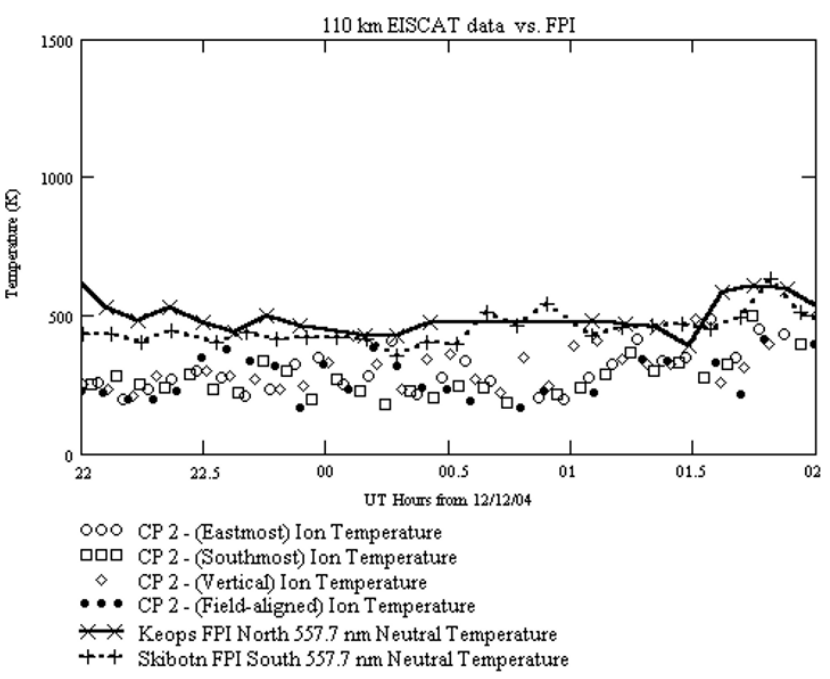

Fig. 9. As for Fig. 6 but EISCAT ion temperatures are from $110 \mathrm{~km}$.

for all 4 of the scan positions compared to the Skibotn South and Keops North FPI neutral temperatures for 2200 UT to 0200 UT. There is evident consistency between the FPI neutral temperature measurements throughout and a large degree of scatter after 0000 UT in the EISCAT measurements. This scatter later in the period is not a feature restricted to any given scan position, and may indicate a period of sustained joule heating. In this comparison we see that throughout this period the EISCAT temperatures are consistently higher than the FPI temperatures. This indicates that the FPI data is never associated with altitudes as high as $126 \mathrm{~km}$ throughout the 2200 to 0200 UT period, given the positive gradient in neutral temperature with altitude in this region.

Figure 7 is similar to Fig. 6, but in this figure we compare the same FPI temperatures to the EISCAT ion temperatures at $120 \mathrm{~km}$. The Figure demonstrates that from $2200 \mathrm{UT}$ until 0000 UT there is very good agreement between the 3 sets of temperature determinations, however after this the ion temperatures tend to be larger than the neutral temperatures, albeit with a large degree of scatter. 
(a)

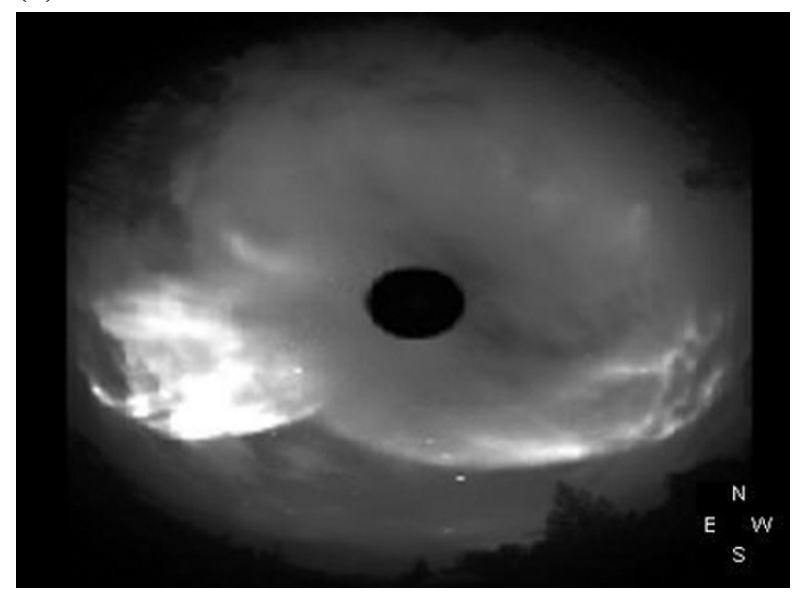

(b)

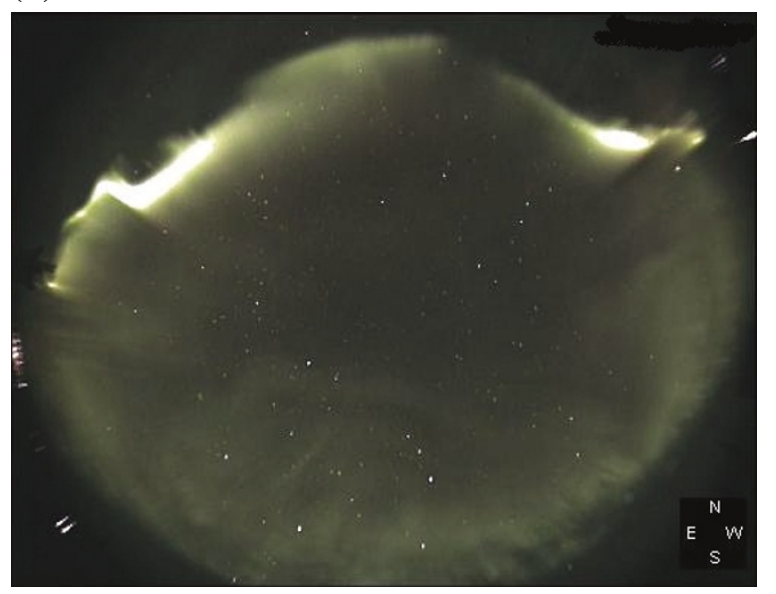

Fig. 10. All sky camera images from (a) Skibotn from the SCASI instrument at 003301 UT and (b) ASC at Keops at 003308 UT. The orientations are indicated on both images.

Figure 8 is again similar to Fig. 6, but in this figure the EISCAT ion temperatures are associated with an altitude of $115 \mathrm{~km}$. In this comparison we see that while for the 2200 UT to 0000 UT period the EISCAT temperatures are consistently less than the FPI temperatures, in the period after this from 0000 UT to 0200 UT the agreement is much better.

Figure 9 is also similar to Fig. 6, but in this figure we compare the same FPI temperatures to the EISCAT ion temperatures at $110 \mathrm{~km}$. In this comparison we see that for the 2200 UT to 0000 UT period the EISCAT temperatures are consistently less than the FPI temperatures, as was the case at $115 \mathrm{~km}$, but here in the period from 0000 UT to 0200 UT the ion temperatures are also consistently lower.

These comparisons allow us to draw conclusions about the height of the $557.7 \mathrm{~nm}$ emission throughout this period. It appears that for the earlier period from 2200 UT to 0000 UT that the emission was close to $120 \mathrm{~km}$, and certainly not as high as $126 \mathrm{~km}$. Later from 0000 UT to 0200 UT the layer was at a lower altitude of around $115 \mathrm{~km}$, but certainly not as low as $110 \mathrm{~km}$. These data are consistent with the high latitude results referred to earlier (e.g. Kosch et al., 2000).

\subsection{All sky camera data}

Figure 1 shows the $557.7 \mathrm{~nm}$ ASC image obtained from Kilpisjarvi at 0034 UT, with the FPI, EISCAT and DELTA positions also indicated. We can see from this image that at the time that the rocket trajectory reached the lower thermosphere, an auroral arc aligned in the east-west direction was observed. This is consistent with images from the broadband (white light) Skibotn ASC (Fig. 10(a)) at 003301 UT and the broadband Keops ASC (Fig. 10(b)) at 003308 UT. Both the Skibotn and Keops ASCs reveal more diffuse but persistent auroral activity after 0100 UT to the end of the night.

The high time resolution of the Kilpisjarvi ASC allows the development of the aurora over this period to be tracked. It is evident that the arc observed was one of several passing zonally from West to East during the period from 0030 UT to 0038 UT (see Fig. 1, Kurihara et al., 2006). Each of these arcs passed overhead at the Andoya and Skibotn sites, and to the North of the Keops site.

\section{Lower Thermosphere Context at the Time of the DELTA Launch}

In this section we examine the results from the groundbased instruments at the time of the DELTA rocket launch in more detail.

\subsection{DELTA rocket launch}

The DELTA rocket launched at 003300 UT on 13/12/04 and reached an altitude of $140 \mathrm{~km}$ at $003604 \mathrm{UT}$ before dropping below $100 \mathrm{~km}$ at $003735 \mathrm{UT}$. On the upward leg the rocket reached $120 \mathrm{~km}$ at $003500 \mathrm{UT}$ and at $003710 \mathrm{UT}$ on the downward leg. Cloud free conditions were apparent at the Andoya, Skibotn and Keops optical sites with the auroral arc visible at each site, as presented earlier.

Kurihara et al. (2006) report neutral temperatures at 120 $\mathrm{km}$ close to $500 \mathrm{~K}$ from the NTV instrument on board the DELTA rocket. It is not intended to repeat the results presented in this paper but it is important to point out that this provides very good agreement with the FPI and EISCAT measurements presented here.

\subsection{Combined ASC, FPI and EISCAT at launch}

Earlier the EISCAT data from 2200 UT to 0100 UT was compared to the FPI neutral temperatures in Figs. 6-9. Here we look in closer detail at the comparisons at the time of the rocket launch using only the FPI temperatures as the degree of scatter after 0000 UT in the EISCAT data, evident in Figs. 6-9, makes detailed examination difficult.

Figure 11 is equivalent to Fig. 2, showing the neutral temperatures measured to the Northwest from Keops and West from Skibotn, but here we look in greater detail at the period from 2300 to 0200 UT and the time of the DELTA rocket launch is indicated on the Figure. There is very good agreement just before launch time with temperatures just below the $500 \mathrm{~K}$ level. The peak in temperature seen just after the launch is seen earliest in the Skibotn West temperatures, although this peak is confined to a single point and there is a rapid recovery to the background level. In the Keops Northwest temperatures the peak is wider and 


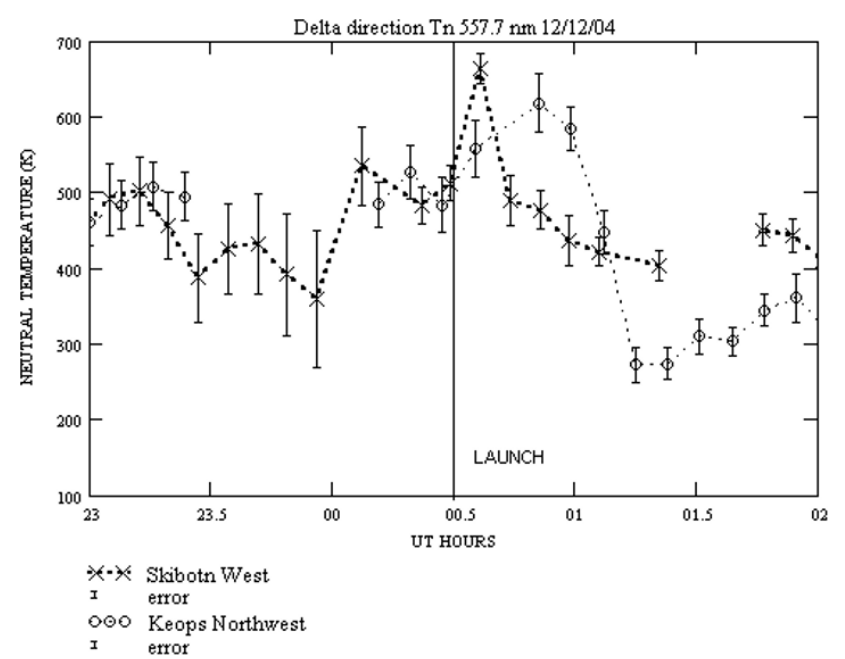

Fig. 11. Lower thermosphere neutral temperatures from 2300 UT on $12 / 12 / 04$ to 0200 UT on $13 / 12 / 04$, observed from the West direction at Skibotn (crosses with heavy dotted line) and from the North-West direction at Keops (circles with light dotted line). Error bars are included for each set of measurements.

the subsequent drop in temperature is to a much lower level $(\sim 300 \mathrm{~K})$ than that seen before the rocket launch $(\sim 500 \mathrm{~K})$.

Figure 12 is equivalent to Fig. 11 but this time for the Keops North and Skibotn South neutral temperatures. The comparison of these temperatures from the closest sampled directions gives further confidence to these estimates of temperature. Some differences may be expected as the samples do not overlap completely but in general the temperatures show very good agreement. Prior to launch time we see temperatures which appear slightly lower than those compared in Fig. 11, within the 400-500 K range. Again we see the temperature peaking after the rocket launch but with a different pattern to that seen in Fig. 11. In this case while the Keops North temperatures appear to peak at a roughly equivalent time to those from Keops Northwest, the Skibotn South peak is now later than that seen in Skibotn West, and coincident with that from Keops North.

To further examine the peak in temperature just after the DELTA rocket launch Fig. 13 shows the neutral temperatures in the 2300 to 0200 UT from all of the Skibotn look directions. In each direction we see a peak after 0030 UT, with the first peak seen in the temperatures from the West, then North, followed by the East and South temperatures. The temperatures then fall back to a level between $400 \mathrm{~K}$ and $500 \mathrm{~K}$ over the 0100 to $0200 \mathrm{UT}$ period. The progression of the peak from West to East suggests that these peaks are related to the zonal progression of the auroral arcs at this time which we have already noted. The possible cause of these temperature peaks is complicated however by the passive nature of the measurements, which suggests an alternative mechanism to direct heating at a particular altitude. This alternative is a feature commonly seen in green line temperatures as the peak altitude of emission may change dramatically in high activity. The presence of the auroral arc at this time could be altering the emission profile and causing a shift to higher altiudes. However, the overall picture when comparing the EISCAT and FPI temperatures is

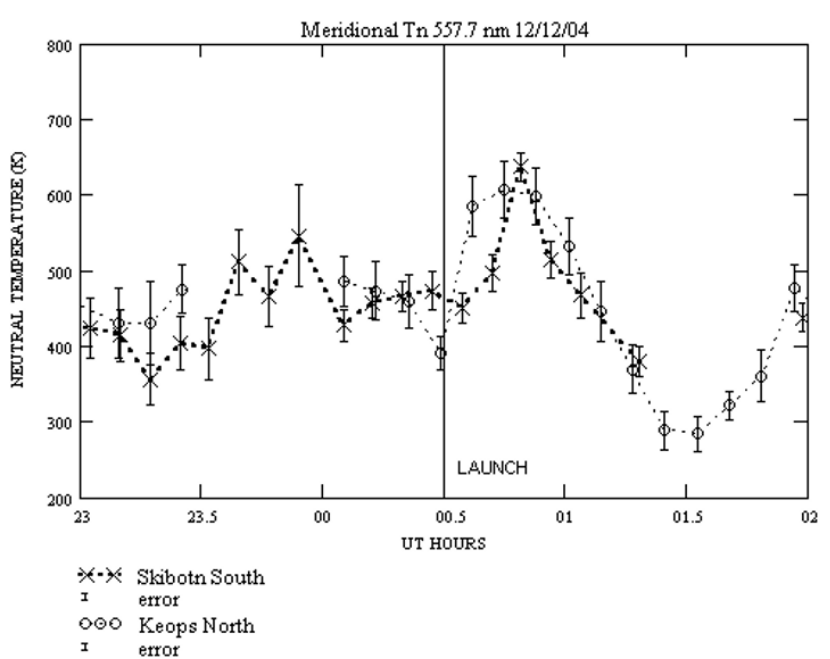

Fig. 12. Lower thermosphere neutral temperatures from 2300 UT on $12 / 12 / 04$ to 0200 UT on $13 / 12 / 04$, observed from the South direction at Skibotn (crosses with heavy dotted line) and from the North direction at Keops (circles with light dotted line). Error bars are included for each set of measurements.

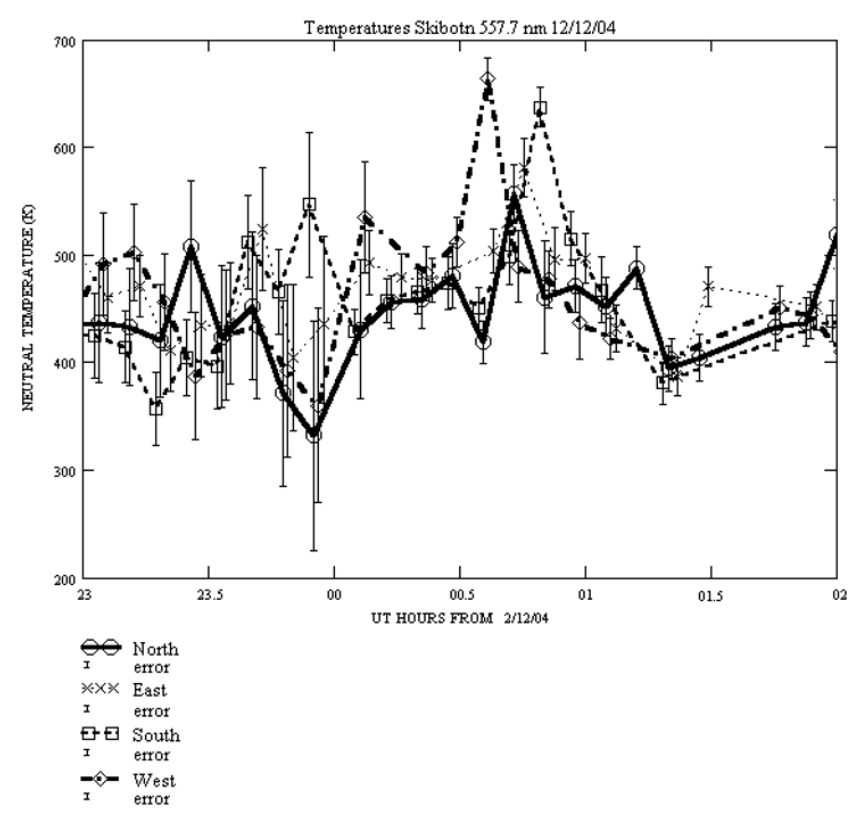

Fig. 13. Combined neutral temperatures from Skibotn from 2300 UT on $12 / 12 / 04$ to 0200 UT on 13/12/04. Temperatures to the North (circles with solid line), East (crosses with light dotted line), South (boxes with heavy dotted line) and West (diamonds with dash-dot line) have error bars included.

that the later period is characterised by a lower emission height. This leads to the conclusion that the temperature peaks seen in the Skibton data are more probably actual changes at this lower $115 \mathrm{~km}$ altitude rather than a sharp rise and drop in emission altitude.

When we consider these changes in temperature in the context of the EISCAT ion temperature measurements we see that the likely altitude of the green line emission prior to the rocket launch is likely to be closer to $115 \mathrm{~km}$ than either $120 \mathrm{~km}$ or $110 \mathrm{~km}$. The DELTA rocket in-situ measurements (see Kurihara et al., 2006), however, would suggest that the green line emission neutral temperatures are 


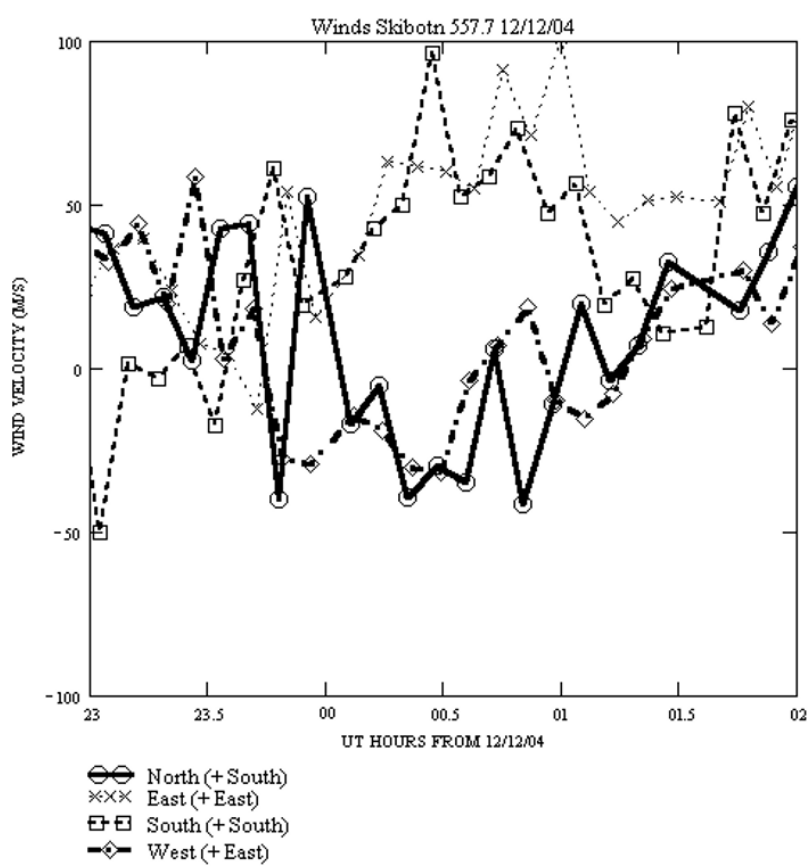

Fig. 14. Combined neutral winds from Skibotn from 2300 UT on 12/12/04 to 0200 UT on $13 / 12 / 04$, for the North (circles with solid line), East (crosses with light dotted line), South (boxes with heavy dotted line) and West (diamonds with dash-dot line). Meridional winds are considered positive Southward, zonal winds are considered positive Eastward.

closer to an altitude of around $120 \mathrm{~km}$. The error bars attributable to the individual measurements, combined to the lack of a direct overlap in the individually sampled volumes make it difficult to draw any more detailed estimate than the $115 \mathrm{~km}$ to $120 \mathrm{~km}$ range as being the most probable emission altitude in the 0000 UT to 0100 UT period. This is encouraging however, as it fixes the emission at an altitude where the comparison of EISCAT ion temperatures and FPI neutral temperatures can be considered reliable.

Separate to these considerations is the possibility of a transient shift in emission altitude related to the passage of the auroral arcs seen at the time of the DELTA rocket launch. The peaks in temperature seen in the Skibotn and Keops data may either be interpreted as reflecting a general heating of the lower thermosphere or a shift in altitude related to the passage of the auroral arcs. We can make use of the other contextual data provided by the ground-based instrumentation to investigate this further.

Figure 14 shows another interesting feature from the Skibton data around launch time. The Figure plots the wind data for the period of the launch with Southward and Eastward directions positive for the meridional and zonal winds respectively. Directly after the launch there is an apparent divergence in the winds with the North and South winds separating, and also the East and West winds separating. Both meridional and zonal winds then converge again by 0130 UT.

In Fig. 15 we see the zenith winds from Skibotn for the night. There is quite a lot of variation but the section highlighted by the thicker line picks out the 0000-0100 UT period which demonstrates the most positive winds of the night, showing upwelling during this period. This is

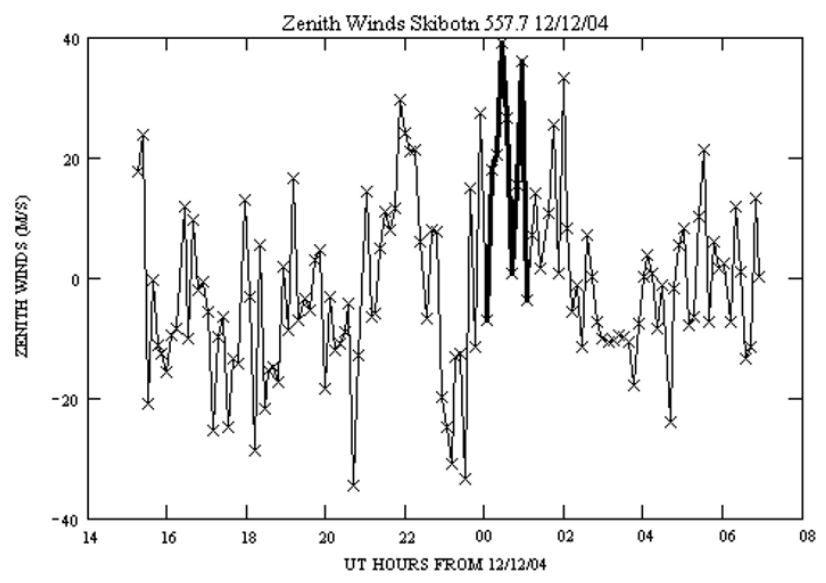

Fig. 15. Zenith neutral winds from the Skibotn FPI for the period from from 1400 UT on $12 / 12 / 04$ to 0800 UT on $13 / 12 / 04$, upwards considered positive. The region highlighted by the heavier line is from 0000 to $0100 \mathrm{UT}$ on $13 / 12 / 04$.

made clearer by contrast with the period of consistent downwelling in the hour before midnight.

These features in the horizontal and zenith winds suggest that the dramatic changes seen in the temperature peaks in each direction are actually more likely to represent a transient general heating in the lower thermosphere rather than a shift in the emission altitude. This would be consistent with the joule heating result, again using EISCAT and Skibotn FPI data, presented by Cierpka et al. (2000).

\section{Conclusions}

The DELTA rocket launch has provided a unique opportunity to combine ground based and in-situ measurements to advance the investigation of the high latitude lower thermosphere. Specifically the comparison of the neutral temperatures measured by the combined set of instruments gives important insight into the detailed response of the atmosphere to auroral activity. In this paper we have shown that the FPI neutral temperatures have proved consistent not only with one another but also with the EISCAT ion temperatures, when viewed in the context of the DELTA rocket measurements. The identification of the $115-120 \mathrm{~km}$ region as the peak emission altitude for the green line at this high latitude site adds an important extra dimension to these normally passive measurements.

Within the combined datasets there are also a number of interesting features observed. Temperatures from Skibotn show a series of peaks close to the time of the DELTA launch which indicate a general heating of the lower thermosphere, reflecting the influence of the local auroral arc, although the possibility of a change in emission altitude cannot be discounted. The other neutral parameters appear to be consistent with the former explanation as there appears to be a period of upwelling through the 0000-0100 UT period consistent with the appearance of a divergence in the wind pattern at this time. There is also the possibility that particle precipitation is causing the heating observed in this period, and this will be considered in further examinations of the data.

Further work with this combined dataset will seek to ad- 
dress the consistent discrepancies between the Skibotn and Keops temperatures later in the night. These may be related to the persistent, diffuse auroral activity later in the night, which appears to be associated with a general lowering of the peak green line emission altitude when viewed in the context of the EISCAT results. In this region ion-neutral coupling is important in determining the effects of geomagnetic activity on the measured parameters, however the extent to which this coupling takes place is difficult to establish in the absence of both ion and neutral density measurements. In this context in-situ rocket measurements are extremely valuable as they will allow numerical models, such as the UCL CMAT model (Dobbin, 2005), to be constrained with relevant data to allow further investigation of the driving mechanisms behind the dynamic changes in temperature and winds seen in the lower thermosphere on the night of the DELTA rocket launch.

Acknowledgments. The authors would like to acknowledge the Finnish Meteorological Institute and thank them for providing both the IMAGE magnetometer data and Kilpisjarvi ASC image used in the paper. We would also like to thank the University of Troms $\varnothing$ and Swedish Space Corporation for providing support and assistance at Skibotn and Keops respectively.

\section{References}

Abe, T., J. Kurihara, N. Iwagami, S. Nozawa, Y. Ogawa, R. Fujii, H. Hayakawa, and K. Oyama, Dynamics and Energetics of the Lower Thermosphere in Aurora (DELTA) - Japanese sounding rocket campaign, Earth Planets Space, 58, this issue, 1165-1171, 2006.

Aruliah, A. L., E. M. Griffin, A. D. Aylward, E. A. K. Ford, M. J. Kosch, C. J. Davis, V. S. C. Howells, S. E. Pryse, H. R. Middleton, and J. Jussila, First direct evidence of meso-scale variability on ion-neutral dynamics using co-located tristatic FPIs and EISCAT radar in Northern Scandinavia, Ann. Geophys., SRef-ID: 1432-0576/ag/2005-23-147, 2005.
Cierpka, K., M. J. Kosch, M. T. Rietveld, K. Schlegel, and T. Hagfors, Ionneutral coupling in the high-latitude F-layer from incoherent scatter and Faby-Perot measurements, Ann. Geophys., 18(9), 1145-1153, 2000.

Dobbin, A., Modelling studies of possible coupling mechanisms between the upper and middle atmosphere, PhD Thesis, University of London, UK, 2005.

Hall, C. M., A. P. van Eyken, and K. R. Svenes, Plasma density over Svalbard during the ISBJØRN campaign, Ann. Geophys., 18, 209-214, 2000.

Ishii, M., M. Kubota, M. Conde, R. W. Smith, and M. Krynicki, Vertical wind distribution in the polar thermosphere during Horizontal E region Experiment (HEX) campaign, J. Geophys. Res., 109, A12311, doi:10.1029/2004JA010657, 2004.

Kosch, M. J., M. Ishii, S. Nozawa, D. Rees, K. Cirepka, A. Kohsiek, K. Schlegel, R. Fujii, T. Hagfors, T. J. Fuller-Rowell, and C. Lathulliere, A comparison of thermospheric winds and temperatures from FabryPerot interferometer and EISCAT radar measurements with models, Adv. Space Res., 26(6), 979-984, 2000.

Kurihara, J., T. Abe, K.-I. Oyama, E. Griffin, M. Kosch, A. Aruliah, K. Kauristie, T. Ogawa, S. Komada, and N. Iwagami, Observations of the lower thermospheric neutral temperature and density in the DELTA campaign, Earth Planets Space, 58, this issue, 1123-1130, 2006.

Price, G. D., R. W. Smith, and G. Hernandez, Simultaneous measurements of large vertical winds in the upper and lower thermosphere, J. Atmos. Terr. Phys., 57, 631-643, 1995.

Taylor, M. J. and M. J. Hill, Near infrared imaging of hydroxyl wave structure over an ocean site at low latitudes, Geophys. Res. Lett., 18 , 1333-1336, 1991.

Thuillier, G., C. Lathuillere, M. Herse, C. Senior, W. Kofman, M. L. Duboin, D. Alcayde, F. Barlier, and J. Fantanari, Co-ordinated EISCATMICADO interferometer measurements of neutral winds and temperatures in E- and F-regions, J. Atmos. Terr. Phys., 52, 625-636, 1990.

Yee, J. H. and V. J. Abreu, Mesospheric 5577 Angstrom green line and atmospheric motions-Atmosphere Explorer satellite observations, Plan. Space Sci., 35, 1389-1395, 1987.

E. Griffin (e-mail: eoghan@apl.ucl.ac.uk), M. Kosch, A. Aruliah, A. Kavanagh, I. McWhirter, A. Senior, E. Ford, C. Davis, T. Abe, J. Kurihara, K. Kauristie, and Y. Ogawa 